\title{
Registro e análise de estruturas relacionadas com a tectônica extensional do rifteamento Macaúbas na Serra Central, norte de Minas Gerais
}

\author{
Record and analysis of structures related to the extensional tectonics \\ of Macaúbas rifting in the Central ridge, north of Minas Gerais
}

\author{
Samuel Moreira Bersan ${ }^{1}$, André Danderfer Filho ${ }^{1}$ \\ ${ }^{1}$ Programa de Pós-graduação, Departamento de Geologia, Universidade Federal de Ouro Preto - UFOP, Campus Morro do \\ Cruzeiro, s/n, Bauxita, CEP 35400-000, Ouro Preto, MG, BR (samuelbersan@gmail.com; danderferandre@gmail.com)
}

Recebido em 13 de setembro de 2016; aceito em 10 de julho de 2017

\begin{abstract}
Resumo
Na região norte da faixa Araçuaí, no domínio fisiográfico do Espinhaço Central, existem registros de bacias sedimentares superpostas instaladas sobre o embasamento do cráton São Francisco. Nesse contexto, a morfoestrutura da Serra Central, norte de Minas Gerais, é sustentada por uma sucessão siliciclástica do Supergrupo Espinhaço superposta a oeste por diamictitos da base do Grupo Macaúbas, representando os registros de rifteamento superpostos ao final do Esteniano e do Toniano Superior, respectivamente. No bordo oeste da Serra Central, são descritas estrias de média a alta obliquidade desenvolvidas sobre os planos de acamamento da sucessão do Grupo Sítio Novo, incompatíveis com a tectônica compressional Brasiliana, que afeta essas rochas. Essas estrias são associadas a degraus e definem vetores de deslizamento interestratais indicativos de movimentação normal a normal destral. Associados a essas lineações, ocorrem veios que também apontam para a atuação de um campo de esforço extensional, com componente destral associada. A análise cinemática e dinâmica dessas estruturas permitiu a interpretação de um regime tectônico distensivo de natureza transtrativa destral e, possivelmente, relacionado ao evento de rifteamento Macaúbas. Nesse cenário, o bloco de capa regional do rifte Macaúbas, representado pela sucessão esteniana do Grupo Sítio Novo, foi deformado sob a atuação de um cisalhamento antitético, com desenvolvimento de um rollover associado. No flanco frontal do rollover, as camadas experimentaram significativa magnitude de rotação, revelando elevado mergulho próximo à borda de falha e favorecendo o desenvolvimento do deslizamento interestratal.
\end{abstract}

Palavras-chave: Análise estrutural; Rifte Macaúbas; Deformação de rollover; Tectônica extensional.

\begin{abstract}
In the northern area of Araçuaí belt, in the central Espinhaço physiographic domain, there are records of superimposed sedimentary basins installed over the São Francisco cratonic basement. In this context, the morphostructure of the Central ridge, north of Minas Gerais, is supported by a siliciclastic succession of Espinhaço Supergroup that are superimposed to the west by the diamictic base of Macaúbas Group. These groups represent two overlapping rifting events in the end of Stenian and upper Tonian respectively. On the western edge of the Central range, high obliquity striated marks, incompatible with the Brasiliano compressional tectonics affecting these rocks, are described on bedding planes of the Sítio Novo Group succession. These marks are associated with orthogonal steps and define sliding vectors indicative of normal to normal destral movement. Associated with these lineations, veins occur, suggesting an extensional stress field, with an associated destral component. The kinematic and dynamic analysis of these structures accords the interpretation of an extensional tectonic regime, presenting a destral-transtensional nature, possibly related to the Macaúbas rifting event. In this scenario, the regional hanging wall of Macaúbas rift, represented by the Stenian succession of the Sítio Novo Group, indicates deformation under the action of an antithetic shear, with development of an associated rollover. The frontal limb layers of the rollover experienced significant magnitude of rotation, revealing high angle dip on the edge of the master fault and, then, favoring the development of interestratal slip.
\end{abstract}

Keywords: Structural analysis; Macaúbas rift; Rollover deformation; Extensional tectonics. 


\section{INTRODUÇÃO}

Sucessões sedimentares pré-cambrianas representam parte do registro de preenchimento de antigas bacias. Em geral, a caracterização desses pacotes permite inferir sobre o sítio tectônico que acolheu a sedimentação e o regime tectônico predominante no local (p.ex., Danderfer e Dardenne 2002; Costa, 2013; Guadagnin et al., 2015; Uhlein et al., 2015). No entanto, são raras as vezes em que se utiliza o registro estrutural para fundamentar a interpretação da tectônica formadora de uma bacia sedimentar, sobretudo nos casos em que ela experimentou deformação durante processos orogênicos. Durante o mapeamento estrutural de sucessões sedimentares deformadas é imprescindível dar especial atenção a determinadas estruturas que possam ser inconsistentes com processos de inversão tectônica e sim compatíveis com um mecanismo de geração da bacia.

Na porção ocidental do paleocontinente São FranciscoCongo, no bloco São Francisco, registros de eventos formadores de bacias se estendem do Paleoproterozoico ao Neoproterozoico e compõem o aulacógeno do Espinhaço, que remonta a uma história policíclica de mais de um bilhão de anos (Moutinho da Costa e Inda, 1982; Danderfer e Dardenne, 2002; Danderfer et al., 2009, 2015), conforme ilustrado na Figura 1A. Nesse sentido, o aulacógeno do Espinhaço representa uma zona de fraqueza crustal no interior da qual o processo tectônico de formação de bacias recorreu ao longo do tempo de existência de grandes massas continentais, como
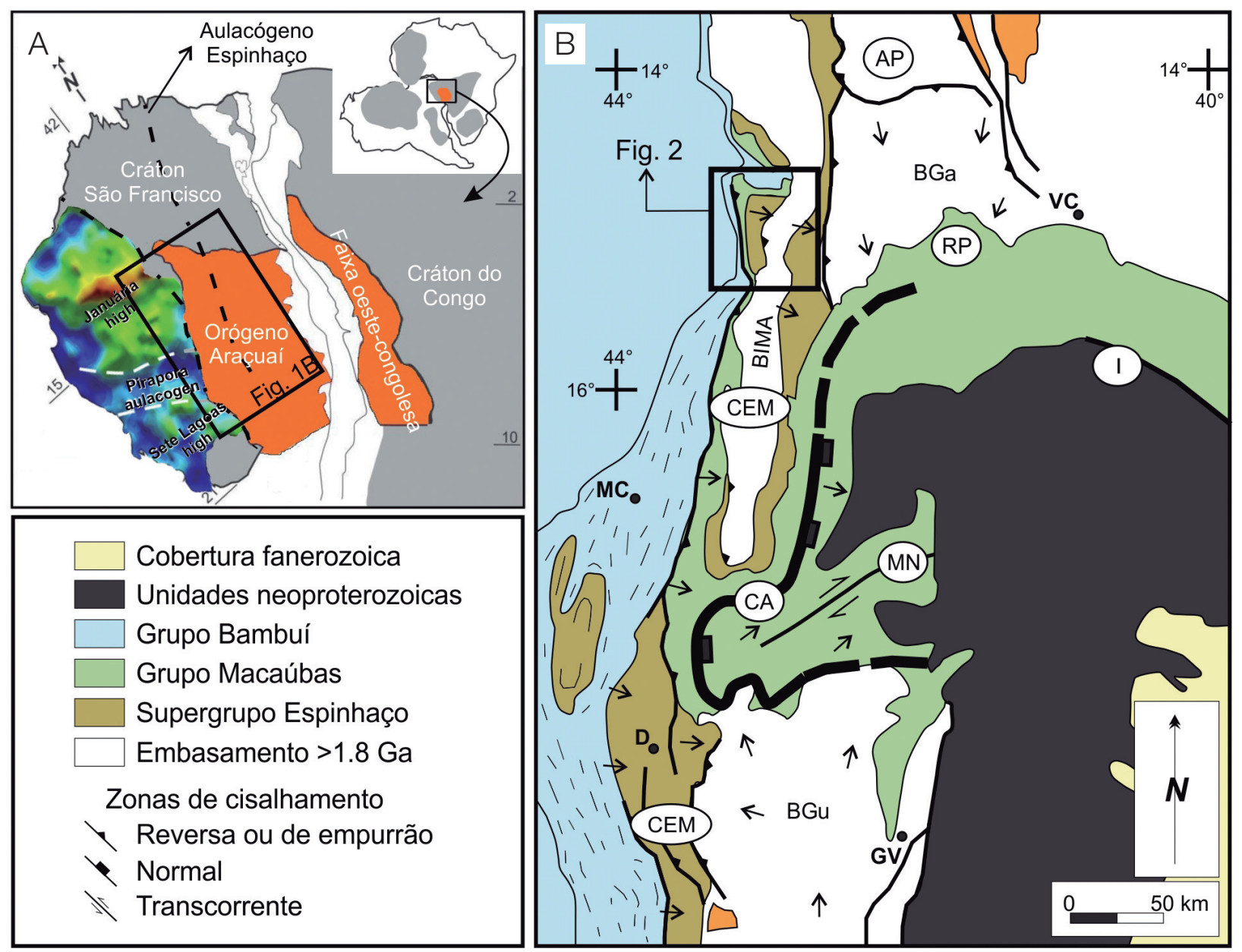

BGu: Bloco Guanhães; BGa: Bloco Gavião; BIMA: Bloco Itacambira-Monte Azul; CEM: Cinturão de cavalgamentos da Serra do Espinhaço; MN: Corredor transpressivo de Minas Novas; S: Zona de dobramentos Salinas; RP: Saliência do Rio Pardo; Zonas de cisalhamento: CA: Chapada de Acauã; I: Itapebi; GV: Governador Valadares; D: Diamantina; MC: Montes Claros; VC: Vitória da Conquista

Figura 1. Contexto geotectônico da área estudada. (A) Localização no contexto do Gondwana ocidental com destaque para a configuração geotectônica do cráton São Francisco-Congo e do orógeno Araçuaí (modificado de Pedrosa-Soares et al., 2007; mapa bouguer modificado de Reis, 2011); (B) Compartimentação tectônica do orógeno Araçuaí com destaque para a posição da área de estudo (modificado de Alkmim et al., 2007). 
as dos supercontinente Columbia e Rodínia(Hoffman, 1991; Zhao et al., 2004; Li et al., 2008; Cawood et al., 2016).

A porção meridional da estrutura aulacogênica, ao sul do paralelo $14^{\circ} \mathrm{S}$ da Figura $1 \mathrm{~B}$, foi fortemente afetada por deformações relacionadas com a orogênese Brasiliana (Neoproterozoico) e passou a integrar o sistema de cavalgamentos da Serra do Espinhaço Meridional na porção ocidental do Orógeno Araçuaí, onde o embasamento é envolvido na deformação da cobertura (Alkmim et al., 2006, 2007), conforme ilustrado na Figura 1B. De forma geral, as coberturas do aulacógeno Espinhaço são descritas nos supergrupos Oliveira dos Brejinhos (1,8 - 1,5 Ga), Espinhaço (1,5 - 1,0 Ga) e São Francisco - Neoproterozoico (Danderfer e Dardenne, 2002; Danderfer et al., 2015). O último registro de formação de bacia é definido pela sucessão siliciclástica do Grupo Macaúbas, interpretada como o preenchimento de um rifte seguido de uma margem passiva (PedrosaSoares et al., 2001, 2011).

Na região da Serra Central, localizada na porção setentrional do cinturão de dobras e cavalgamentos da Serra do Espinhaço - CEM (Figuras 1B e 2), ocorrem

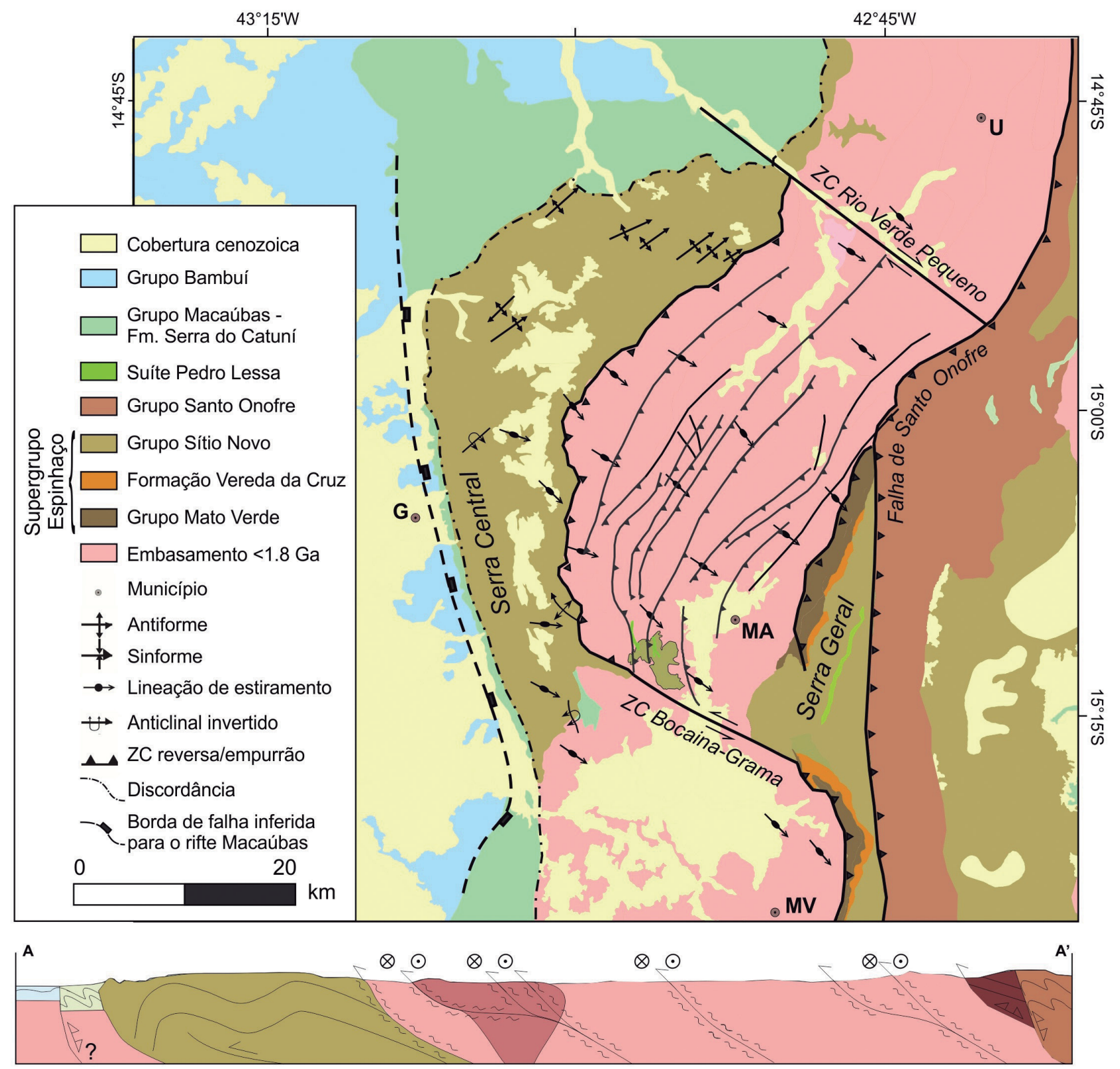

ZC: zona de cisalhamento

Figura 2. Mapa geológico-estrutural simplificado da área estudada (compilado a partir de Drumond et al., 1980; Souza et al., 2004; Costa, 2013; Bersan, 2015; Knauer et al., 2015). 
metadiamictos relacionados ao preenchimento da fase rifte Macaúbas que sobrepõem as sucessões silicicásticas mais antigas do Supergrupo Espinhaço (Souza et al., 2004; Knauer et al., 2015), conforme ilustrado na Figura 2. Em trabalho voltado à evolução estrutural dessa área, Bersan (2015) caracteriza um domínio de baixa magnitude de deformação na porção ocidental da Serra Central, onde foram reconhecidos registros estruturais sobre as rochas do Supergrupo Espinhaço, que incluem lineações de deslizamento desenvolvidas sobre e plano de acamamento e veios, cujas orientações e cinemáticas se mostram incompatíveis ao evento compressional Brasiliano que afetou esse setor. Com isso, é possível que essas estruturas se associem à tectônica formadora da bacia Macaúbas que se instalou diretamente sobre os estratos do Supergrupo Espinhaço e representa o último evento tectônico que precedeu o evento orogenético Brasiliano.

Este trabalho visa a analisar essas estruturas desenvolvidas nos metarenitos da borda oeste da Serra Central e relacioná-las ao evento tectônico extensional formador do rifte Macaúbas, bem como uma tentativa de reconstrução do paleocampo de esforços vigentes no decorrer dessa deformação extensional. Para o presente estudo foram realizados levantamentos estruturais de detalhe no domínio ocidental da Serra Central, onde os efeitos da deformação compressional Brasiliana são fracamente desenvolvidos, sobretudo ao longo de perfis em drenagens encaixadas com orientação transversal ao trend estrutural. Como base geológica utilizaram-se compilações dos mapas geológicos de Drumond et al. (1980) e Knauer et al. (2007, 2015). O tratamento estatístico dos dados estruturais foi feito com a utilização dos softwares OpenStereo, GeoOrient, GeoCalculator, FaultKin e Win-Tensor. Os diagramas estereográficos apresentados utilizam a projeção Schmidt de igual área e os dados estão plotados no hemisfério inferior. A atitude de planos e linhas está expressa pela notação em trama (direção do mergulho/mergulho). Para a definição do sentido de movimentação sobre os planos de falhas, foram utilizados os critérios de estruturas PT e de cristalização de minerais devido a irregularidades na superfície de falha propostos por Petit (1987). Os resultados aqui alcançados permitem tecer melhores considerações sobre a tectônica formadora da bacia Macaúbas e, por conseguinte, do rifteamento do supercontinente Rodínia nesse local.

\section{CONTEXTO GEOLÓGICO}

No contexto geotectônico, o domínio fisiográfico da Serra Central é posicionado no extremo noroeste do CEM, edificado na porção mais externa do orógeno Araçuaí durante a orogênese Brasiliana, junto ao bordo oriental do cráton São Francisco (Almeida, 1977; Alkmim et al., 1993, 2006), conforme ilustrado na Figura 1B. O CEM registra processos deformacionais relacionados com a tectônica thick-skinned, na qual a deformação foi condicionada pelo envolvimento do embasamento durante a interação colisional dos blocos São Francisco e Congo (Figuras 1A e 1B). Ao leste da Serra Central, o bloco Itacambira-Monte Azul (BIMA) constitui parte do embasamento arqueano-paleoproterozoico do bloco São Francisco que foi retrabalhado no decorrer da orogênese Brasiliana (Figura 1B). Esse bloco baliza o segmento ocidental da cobertura exposta na Serra Central, tendo influenciado diretamente o seu estilo deformacional no decorrer do evento compressional Brasiliano (Crocco-Rodrigues et al., 1993; Bertoldo, 1993; Bersan, 2015), conforme ilustrado nas Figuras 1B e 2.

O empilhamento estratigráfico cartografado na Serra Central é representado por duas sequências siliciclásticas, separadas por discordâncias regionais relacionadas aos dois últimos episódios de rifteamento do bloco São Francisco (Figura 2). A sequência mais antiga integra o intervalo superior do Supergrupo Espinhaço, enquanto a mais nova é relacionada à unidade basal do Grupo Macaúbas (Souza et al., 2004; Knauer et al., 2015). A sequência do Supergrupo Espinhaço consiste basicamente de uma sucessão de metarenitos e metapelitos que se intercalam de forma rítmica (Drumond et al., 1980; Bersan, 2015; Knauer et al., 2015). Localmente, ocorrem leitos de metaconglomerado oligomítico matriz suportado, com seixos e grânulos subarredondados de arenito imersos em uma matriz quartzosa a arcoseana de granulometria média a grossa (Drumond et al., 1980; Bersan, 2015; Knauer et al., 2015). Essa sequência pode ser correlacionada ao Grupo Sítio Novo, definido por Danderfer e Dardenne (2002) ao norte no domínio do Espinhaço Setentrional, cuja deposição foi estimada pelos autores entre 1,2 e 1,0 Ga (Esteniano). A sequência do Grupo Macaúbas, sobreposta em discordância angular sobre o Grupo Sítio Novo, aflora em uma estreita faixa de orientação N-S a NE-SW ao longo da borda oeste da Serra Central. É constituída por metadiamictitos correlacionáveis aos da Formação Serra do Catuni, base do Grupo Macaúbas (Souza et al., 2004; Bertoldo, 1993; Bersan, 2015; Knauer et al., 2015), conforme ilustrado na Figura 2. A idade máxima de deposição para as unidades basais do Grupo Macaúbas tem sido estimada em 900 Ma, a partir de datações realizadas em zircões detríticos (Pedrosa-Soares e Alkmim, 2011; Pedrosa-Soares et al., 2011; Babinski et al., 2012). O pacote da Formação Serra do Catuni é recoberto, na porção oeste, pela sucessão pelítico-carbonática do Grupo Bambuí, relacionada com o preenchimento de uma bacia de antepaís instalada durante a edificação dos orógenos marginais do cráton São Francisco no Ediacariano (Alkmim e Martins Neto, 2001; Martins-Neto e Alkmim, 2001; Martins-Neto et al., 2001; Alkmim e Martins-Neto, 2012; Reis e Suss, 2016). 


\section{Arcabouço estrutural}

A Serra Central configura uma morfoestrutura curva de formato semelhante a um bumerangue assimétrico com orientação NNW-SSE na porção meridional passando à orientação NE-SW ao norte, gerando, assim, uma concavidade voltada para SE no sentido contrário ao da vergência tectônica do CEM, que é de leste para oeste (Figuras 2 e 3).
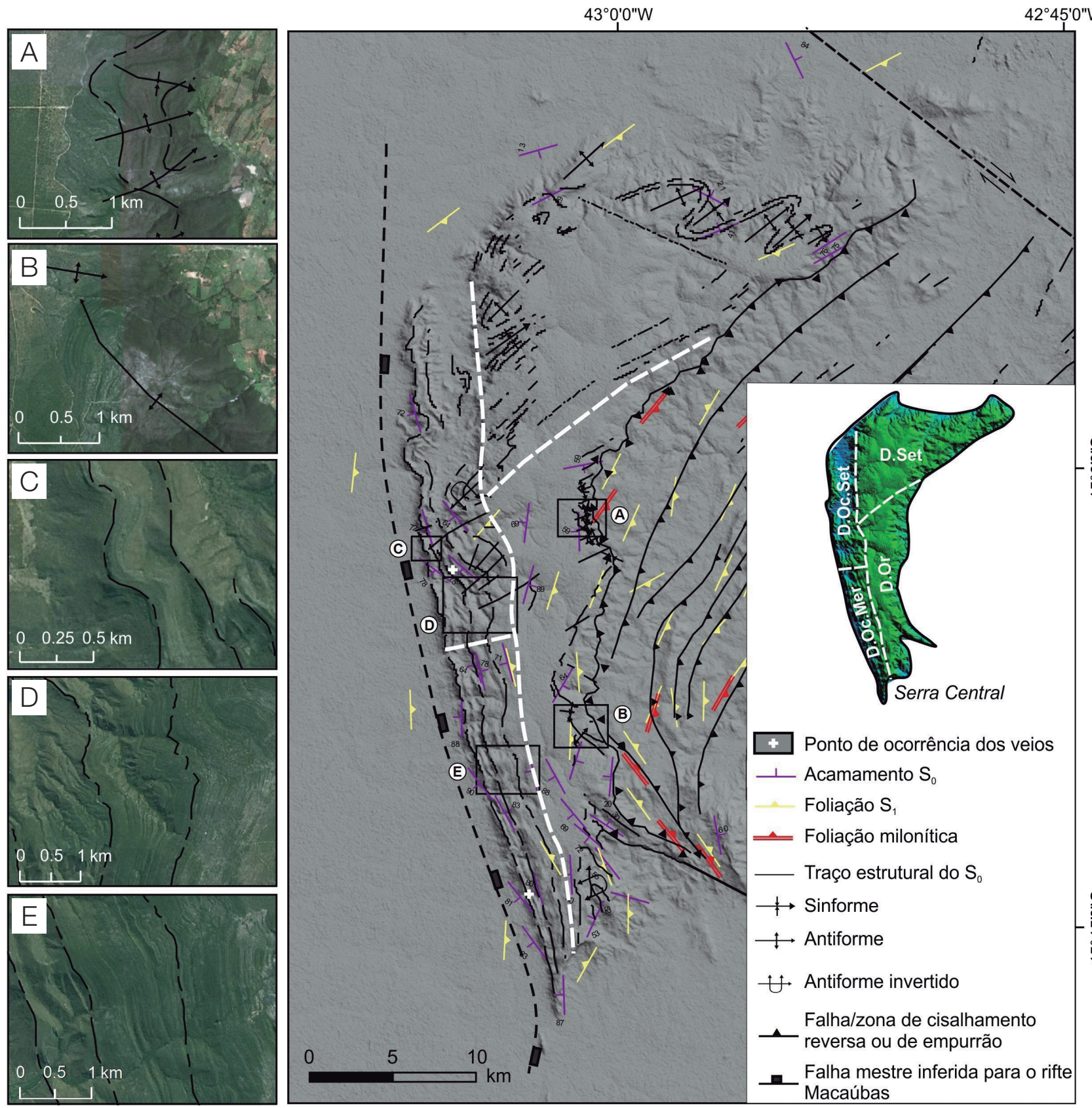

Domínios estruturais: D.Set: Setentrional; D.Or: Oriental; D.Oc.Mer: Ocidental meridional; D.Oc.Set: Ocidental setentrional.

Figura 3. Modelo hillshade da Serra Central com sobreposição da trama estrutural e subdivisão dos domínios estruturais (gerado a partir de modelo digital de elevação SRTM). As figuras (A-E) ilustram as principais megaestruturas observadas no serra Central a partir da análise de imagens de satélite. (A) Padrão de dobramento que se assemelha a dobras em caixa; (B) Anticlinais quilométricos com traços axiais curvos; (C) Dobras subverticais assimétricas indicativas de movimentação sinistral; (D) Dobras com padrão em chevron desenvolvidos na região onde se inicia a inflexão da Serra Central para a direção NE-SW; (E) Sequência sedimentar do Grupo Sítio Novo na borda oeste meridional da Serra Central. Domínios estruturais: D.Set - Setentrional; D.Or - Oriental; D.Oc.Mer - Ocidental meridional; D.Oc.Set - Ocidental setentrional. As linhas tracejadas em branco marcam os limites dos domínios estruturais. 
Bersan (2015), em trabalho sobre a evolução estrutural da área, descreve uma notável diminuição da deformação compressional de leste para oeste, ou seja, em direção ao cráton São Francisco. Segundo o autor, na região leste da Serra Central, onde afloram rochas do embasamento cristalino, ocorrem feixes de zonas de cisalhamento reversas e vergentes para oeste que empurram rochas do embasamento sobre a cobertura exposta no bordo leste da Serra Central. Essas zonas de cisalhamento, cujas direções são subparalelas à trama tectônica das rochas supracrustais expostas na Serra Central, são materializadas por foliações miloníticas e lineações de estiramento associadas que apresentam orientação média de 126/50 e 92/30, respectivamente. Essas zonas de cisalhamento são balizadas ao sul e ao norte por duas zonas de cisalhamento transversais de orientação NW-SE, denominadas, respectivamente, de Bocaina-Grama e Rio Verde Pequeno (Bertoldo, 1993; Bersan, 2015), conforme ilustrado na Figura 2.

Em função de variações na orientação espacial e na frequência das estruturas observadas, bem como da magnitude de deformação atuante, Bersan (2015) divide a morfoestrutura da Serra Central em três subdomínios estruturais (Figura 3). No subdomínio oriental, onde a deformação é mais intensa, são descritos padrões de dobramentos sobre as rochas supracrustais em resposta a duas direções de encurtamento (Figuras 3A e 3B): a) ESE-WNW, induzido pelo envolvimento tectônico do embasamento ao leste, que cavalga a cobertura para oeste; e b) N-S, condicionado pelo alto de Januária, que configura um alto estrutural do embasamento no domínio do cráton São Francisco (Figura 1A). Nesse último caso, o alto de Januária teria atuado como um anteparo rígido oblíquo ao longo dos bordos oeste e norte da Serra Central, favorecendo a partição da deformação por meio de movimentos oblíquos durante o transporte tectônico de massa de ESE para WNW (Bersan, 2015). Uma clivagem $S_{1}$, definida pela reorientação e recristalização planar de micas e agregados ou cristais de quartzo, ocorre em todo o setor com atitude média de 109/30. O subdomínio ocidental é marcado por uma diminuição da deformação compressional materializada pela foliação $S_{1}$, que varia de fraca a ausente. Nesse subdomínio, o acamamento é subverticalizado segundo a direção NNW-SSE. Dobramentos subverticais passam a afetar o acamamento na porção mais setentrional desse subdomínio.

No subdomínio setentrional, o trend principal se dá segundo a orientação NE-SW, destoante do strike NNW-SSE observado para os subdomínios oriental e ocidental. Nesse subdomínio, o encurtamento produziu dobras com traços axiais NE-SW e caimento para NE. Essas dobras mostram geometria fechada próximo ao contato com o embasamento, passando a dobras abertas em direção a NW, indicando, assim, um decréscimo da deformação em direção ao noroeste. A clivagem $\mathrm{S}_{1}$ é plano-axial e apresenta mergulhos para SE, indicando transporte de massa para NW. Segundo Bertoldo (1993) e Bersan (2015), a transição do estilo deformacional entre os segmentos meridional, de trend NNW-SSE, e setentrional, de orientação NE-SW, ocorre de maneira gradativa, com progressiva rotação das tramas planares.

\section{ANÁLISE ESTRUTURAL DESCRITIVA}

Por revelar baixa magnitude deformacional (strain) e preservar bem o acamamento sedimentar e as tramas sedimentares primárias associadas (Figura 4), o setor ocidental da Serra Central se oferece como um local apropriado para a observação de estruturas associadas a eventos tectônicos formadores de bacias sedimentares. Em tais circunstâncias, seria admissível supor que estruturas deformacionais relacionadas ao evento de rifteamento Macaúbas poderiam ser encontradas impressas sobre o embasamento relativo dessa bacia, representado, nesse caso, pela associação de rochas do Grupo Sítio Novo. Dentro desse contexto verificou-se a ocorrência de lineações interestratais e veios incompatíveis com a compressão que afeta a área e cuja gênese possivelmente é atribuída a uma tectônica anterior à deformação Brasiliana.

\section{Acamamento}

O acamamento sedimentar $\left(\mathrm{S}_{0}\right)$ do Grupo Sítio Novo, ao longo da borda ocidental da Serra Central, foi bem marcado pela presença de estratificação/laminação interna, mudanças granulométricas, intercalações de pelito/conglomerado ou pelo próprio empacotamento sedimentar, evidenciado pela existência de planos de acamamento (Figuras 4A, 4B e 4C). Estratificação cruzada tangencial e marcas de onda se encontram bem preservadas e constituem bons indicadores geopetais (Bersan, 2015), conforme ilustrado na Figura 4C. Em geral, o $\mathrm{S}_{0}$ mostra uma pequena variação de sul para norte. No segmento setentrional, o diagrama de distribuição dos polos indica atitude média de 237/81, sendo associado a uma pequena dispersão que pode ser ajustada a uma guirlanda de eixo 243/78 (Figura 5A) e possivelmente reflete uma ação de dobramentos subverticais, conforme observado em imagens de satélite (Figuras 3C, 3D e 3E). Já para a região meridional a orientação da distribuição de polos de $\mathrm{S}_{0}$ é do tipo unimodal, com concentração indicando uma atitude média de 250/88 (Figura 5B). Apesar dessa pequena variação na atitude de $\mathrm{S}_{0}$, os indicadores geopetais observados indicam topo estratigráfico normal para oeste ao longo do segmento ocidental da Serra Central. Localmente, os estratos encontram-se invertidos, com mergulhos de médio ângulo para leste.

Ao contrário do observado para a sequência Sítio Novo, os depósitos de metadiamictito da Formação Serra do Catuni 
(Grupo Macaúbas) são maciços, desorganizados e desprovidos de acamamento (Figura 4D). A matriz dessas rochas varia de siltítica (ao sul) a dominantemente arenítica (ao norte). Contém invariavelmente clastos (seixos a grânulos) de quartzo, metarenitos diversos e rochas quartzo-feldspáticas. Knauer et al. (2015) descrevem ainda clastos de material ocre alterado, provavelmente relacionados à presença de rochas carbonáticas.

\section{Lineação interestratal $\left(L_{s o}\right)$}

Possivelmente em função da baixa magnitude de deformação que atuou sobre as rochas do segmento ocidental da Serra Central, é comum encontrar superfícies com lineações secundárias sobre os planos de acamamento, materializadas pela presença de estrias de atrito, que são aqui relacionadas com uma fase anterior à de inversão tectônica, conforme demonstrado a seguir. Essas estrias são representadas por sulcos desenvolvidos sobre os planos de $\mathrm{S}_{0}$ de metarenitos com boa seleção textural e em rochas de granulação mais fina, como nos estratos tabulares de metapelitos que se intercalam de forma rítmica nos metarenitos. As estrias de atrito podem, por vezes, estar associadas a lineações fibrosas quartzosas. O conjunto estrias de atrito e lineações fibrosas representa, dessa forma, uma lineação interestratal denominada $\mathrm{L}_{\mathrm{s} 0}$ (Figura 4E). Diminutos ressaltos (steps) transversais encontram-se associados à $\mathrm{L}_{\mathrm{s} 0}$. $\mathrm{O}$ conjunto formado pela $\mathrm{L}_{\mathrm{S} 0}$ e respectivos ressaltos permitem a caracterização de um mecanismo de deslizamento interestratal para a origem dessas estruturas encontradas ao longo de toda a borda oeste da Serra Central.

Assim como definido para a orientação de $\mathrm{S}_{0}$, é possível notar uma pequena variação na atitude média da $\mathrm{L}_{\mathrm{S} 0}$ ao longo da borda oeste da Serra Central. No segmento setentrional, a atitude média é de 308/51, passando a 240/84 no setor meridional (Figura 5). De modo geral, a obliquidade entre a $\mathrm{L}_{\mathrm{S} 0}$ e o $\mathrm{S}_{0}$ varia entre moderada e alta. Tal relação angular, somada à presença dos degraus associados com a $\mathrm{L}_{\mathrm{S} 0}$, define vetores de deslizamento interestratais indicativos de movimentação normal a normal com componente destral (Figura 6).

Localmente, a $\mathrm{L}_{\mathrm{S} 0}$ se apresenta com caimentos para SE e cinemática normal sinistral. Tal orientação é destoante da observada para a moda descrita anteriormente e
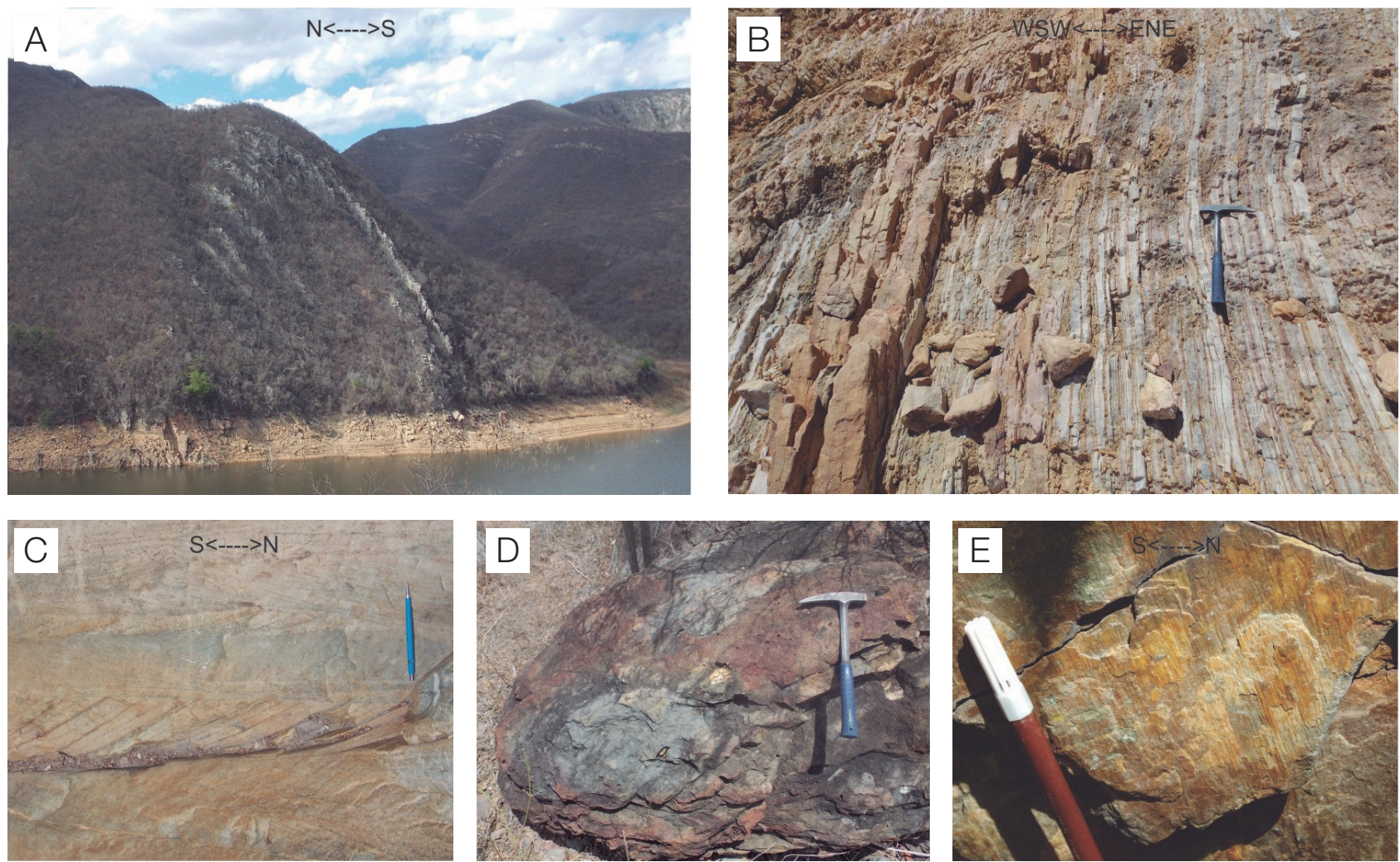

Figura 4. Principais feições do $S_{0}$. (A) Visão geral do acamamento subverticalizado na borda oeste da Serra Central; (B) Detalhe do empacotamento sedimentar bem marcado pela sucessão de camadas subverticais tabulares de metarenito e meta-pelito; (C) Estratificação cruzada tangencial em metarenitos; (D) Diamictito da sucessão basal do Grupo Macaúbas; (E) Estrias $\left(L_{s 0}\right)$ sobre o plano de acamamento (vista da base da camada). 
possivelmente se relaciona à movimentação sinistral que culminou no desenvolvimento dos dobramentos de assimetria sinistral presentes no bordo oeste da Serra Central (Figuras 3C e 3E).

\section{Foliação $\mathbf{S}_{1}$}

Conforme mencionado, a ocorrência da foliação metamórfica $\mathrm{S}_{1}$, desenvolvida em resposta ao evento compressional Brasiliano que afeta a área, não é comum nas rochas do Grupo Sítio Novo expostas na porção ocidental da Serra Central. Quando definida, essa foliação mostra orientação dominante N-S com mergulhos para leste e se destaca como uma xistosidade em rochas de granulação mais fina ou intemperizadas. De maneira geral, a $\mathrm{S}_{1}$ é definida pela reorientação e recristalização planar de micas e agregados ou cristais de quartzo. Nos metadiamictitos do Grupo Macaúbas, a $\mathrm{S}_{1}$ é definida em sua matriz na forma de uma clivagem fracamente desenvolvida e dominada pelos processos de dissolução por pressão. Nessas rochas ela é marcada pela orientação de muscovita/sericita e lamelas muito finas, de coloração escura, residuais do processo de dissolução.

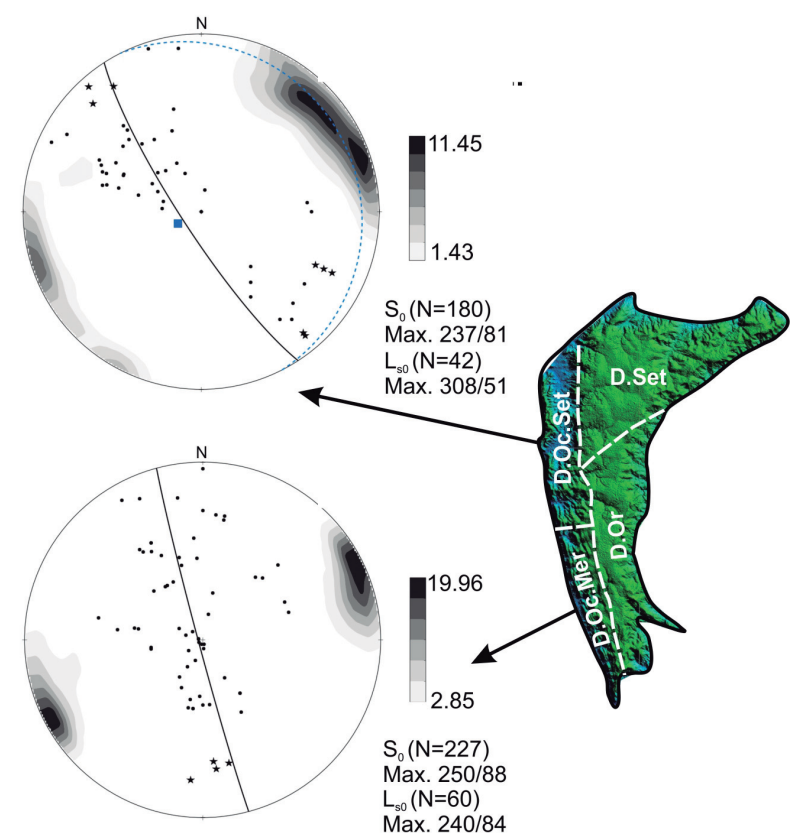

- Ls0 ^ LS0XS1 Guirlanda . Eixo $\pi$

$L_{\text {so: }}$ : lineação interestratal; $L_{\text {soxst }}$ : lineação de interseção entre os planos de acamamento e foliação.

Figura 5. Diagramas estruturais de distribuição do acamamento $S_{0}$ e das lineações associadas para a borda oeste da Serra Central. As distribuições em contorno se referem às tramas planares do acamamento.
Lineações resultantes da intersecção entre os planos $\mathrm{S}_{0}$ e $\mathrm{S}_{1}\left(\mathrm{~L}_{\mathrm{S} 0 \mathrm{xs} 1}\right)$ são raras. Essas feições mostram rumo N-S com caimento de baixo ângulo para sul na porção meridional. No segmento setentrional, a $\mathrm{L}_{\mathrm{s} 0 \mathrm{xS} 1}$ apresenta rumo NW-SE e caimentos de baixo ângulo.

\section{Veios}

Uma diversidade de grupos de veios de quartzo foi descrita por Bersan (2015) na morfoestrutura da Serra Central. Grande parte dos veios descritos ocorre no bordo leste da Serra Central subparalelamente à foliação $S_{1}$ e foi relacionada pelo autor ao evento compressional Brasiliano.

Na borda oeste da Serra Central, é comum a presença de veios de quartzo subparalelos ao $\mathrm{S}_{0}$ que podem apresentar estrias e sulcos de orientação similar à observada para a $\mathrm{L}_{\mathrm{s} 0}($ Figuras $6 \mathrm{~A}$ e $6 \mathrm{~B}$ ). Além disso, ocorre uma família de veios sigmoidais de espessuras milimétricas e mineralogia à base de quartzo, cujas orientações são transversais ao acamamento. Esses veios são raramente descritos (verificados em apenas duas estações geológicas; Figura 3) e, quando observados, apresentam assimetrias em "Z" na vista em planta (com plano de orientação 282/73) e "S" em perfil (com plano de orientação 212/10). Conforme apresentado esquematicamente na Figura 6, esse grupo de veios aponta para a atuação de uma movimentação normal com componente destral no bordo ocidental da Serra Central, movimentação compatível àquela indicada pelas $\mathrm{L}_{\mathrm{S} 0}$.

\section{Dobras}

Imagens de satélite permitem caracterizar a ocorrência de dobras em escala macroscópica que afetam os estratos subverticalizados do Grupo Sítio Novo expostos na região oeste da Serra Central. Conforme ilustrado nas Figuras 3C, $3 \mathrm{D}$ e $3 \mathrm{E}$, essas dobras são verticais e passam de suaves (na região meridional) a fechadas com assimetrias sinistrais (ao norte). A ação desses dobramentos fica clara no diagrama de polos do $\mathrm{S}_{0}$, que mostra uma dispersão para a porção mais ao norte do bordo oeste da serra. Próximo à região de inflexão da Serra Centra é observado um padrão de dobramento em chevron. Não foram observados dobramentos em mesoescala na região. $\mathrm{A} \mathrm{S}_{1}$ descrita, bem como as $\mathrm{L}_{\mathrm{S} 0 \times \mathrm{SI}}$, parece não ter relação genética com esses dobramentos, já que suas orientações não são compatíveis com os dobramentos subverticais caracterizados via imagens de satélite.

\section{ANÁLISE DE PALEOSTRESS}

Determinações aproximadas dos principais campos de esforços atuantes na região podem ser estimadas a partir 
das direções incrementais dos eixos de encurtamento $(\mathrm{P})$ e extensão (T), conforme ilustrado na Figura 7. Os eixos P e T são definidos a partir das relações angulares entre as superfícies de falha e o sentido e a direção de movimentos demarcados pelas lineações associadas (Marrett e Allmendinger, 1990). Os eixos cinemáticos incrementais 11, 12 e 13 são interpretados como subparalelos aos tensores s3, s2 e s1, respectivamente. Diagramas de tangente da lineação são também apresentados na Figura 7. Esses diagramas se mostram uma boa ferramenta geométrica para definir os esforços atuantes a partir de dados de falhas. As direções das setas nos diagramas de tangente de lineação indicam a movimentação do bloco de lapa em relação ao bloco de capa (Fossen, 2010).

A análise para os eixos cinemáticos foi efetuada para as superfícies de deslizamento interestratal ocorrentes no setor investigado. Um dos pressupostos teóricos da análise de paleotensão é de que as rochas tenham experimentado uma única fase de deformação rúptil (Fossen, 2010). Os dados foram tratados a partir dos softwares Faultkin (versão 7.2.9) e Win-Tensor (versão 5.8.6). Para a determinação cinemática, assume-se que não houve reorientação dos dados de slip de falha e que a deformação atuante foi do tipo coaxial e homogênea. Considerações adicionais e limitações desse método são discutidas em Marrett e Allmendinger (1990).

Conforme descrito, no bordo oeste da Serra Central a deformação compressional do Brasiliano é ínfima. É possível que essa deformação tenha causado uma pequena rotação anti-horária dos estratos do Grupo Sítio Novo, entretanto sem geração de estruturas rúpteis que invalidariam a premissa de ocorrência de apenas uma fase deformacional. Dessa forma, é passível de se assumir que as $\mathrm{L}_{\mathrm{S} 0}$ descritas reflitam a fase rúptil do último evento de rifteamento que ocorre na área superposta aos estratos do Grupo Sítio Novo, que teriam atuado como o bloco de capa desse evento. A presença dos veios sigmoidais, cuja gênese é atribuída ao mesmo evento de geração das $\mathrm{L}_{\mathrm{s} 0}$, pode inicialmente contradizer o princípio de que a deformação seja coaxial. Entretanto, como a ocorrência desses veios é muito restrita, pode-se considerar, nesse caso, que a atuação de uma deformação não coaxial seja desprezível.

Para analisar os possíveis efeitos que a rotação anti-horária dos estratos gerou na orientação dos eixos cinemáticos, as análises de paleostress foram realizadas com os dados brutos obtidos em campo e com os dados
A

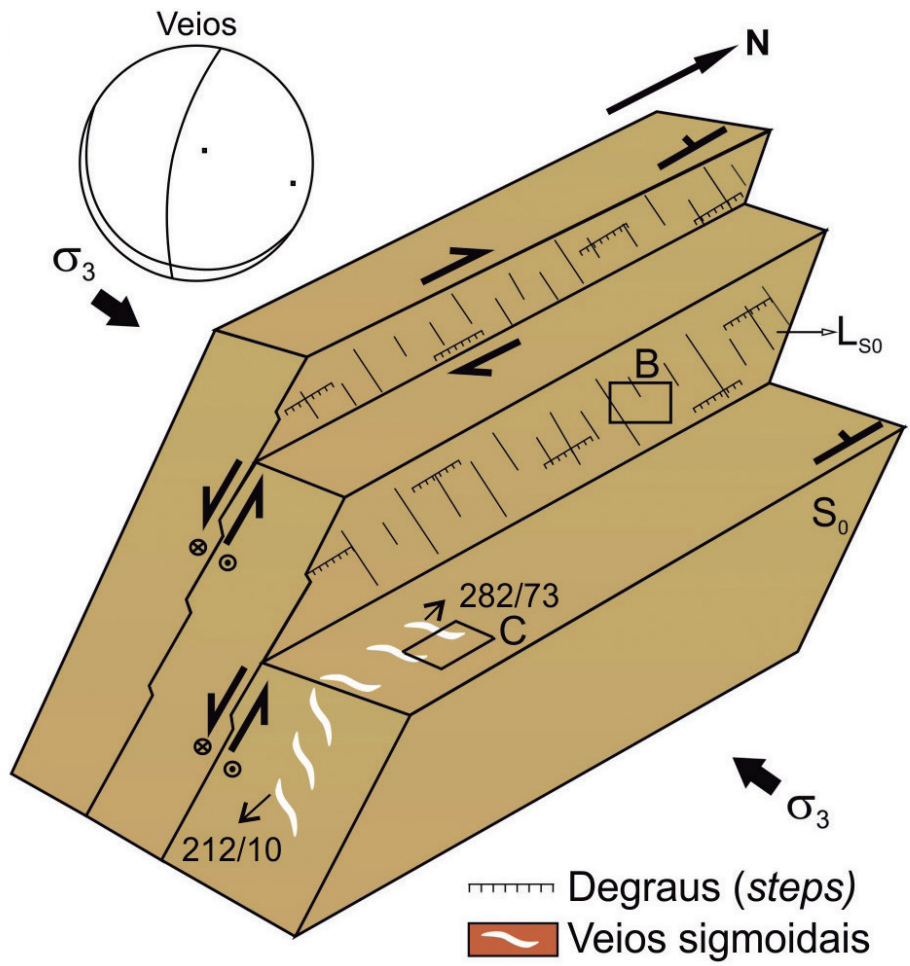

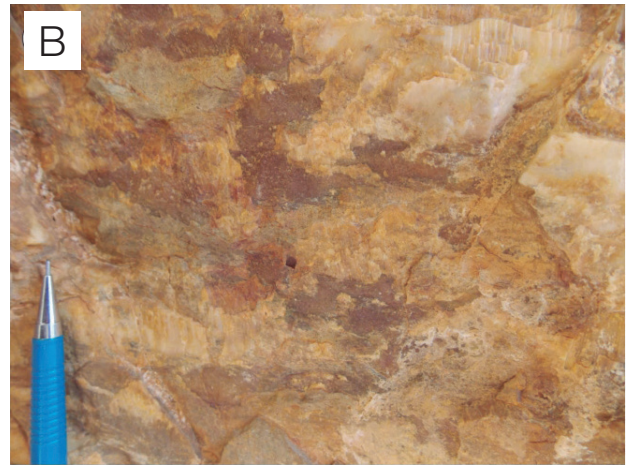

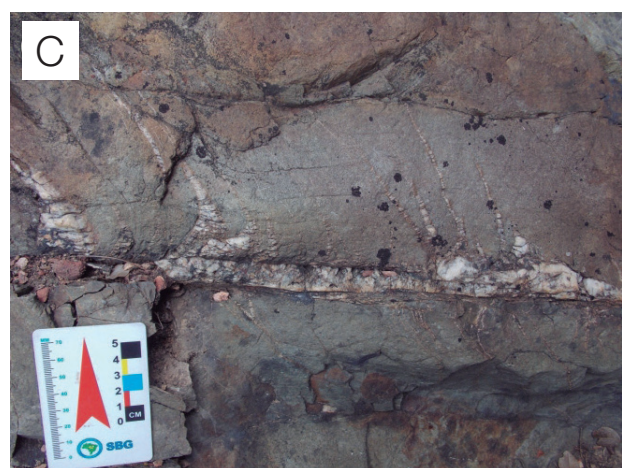

Figura 6. (A) Desenho esquemático ilustrando os elementos estruturais presentes no bordo oeste da Serra Central, indicativos de movimentação normal destral; (B) veios subparalelos ao $\mathrm{S}_{0}$ com estrias e degraus de deslizamento interestratal definidos por fibras quartzosas; (C) veios sigmoidais indicativos de movimentação normal destral. Visão de base para topo em A e B. Em C, visão em planta. 
rotacionados no sentido horário em $30^{\circ}$, segundo um eixo paralelo ao strike do $\mathrm{S}_{0}$. Além disso, visto que a presença de dobramentos subverticais causa uma variação na orientação das superfícies de deslizamento interestratal na porção setentrional da borda oeste da Serra Central (Figuras 3C, 3D, 3E e 5), os dados de paleostress foram analisados separadamente por setor e também de forma agregada (Figura 7). Os setores são divididos em setentrional, onde os dobramentos causam uma pequena dispersão dos dados de $\mathrm{S}_{0}$, e meridional, com dobramentos incipientes ou ausentes e baixa dispersão dos polos de $\mathrm{S}_{0}$ (Figura 3).

\section{Dados rotacionados}

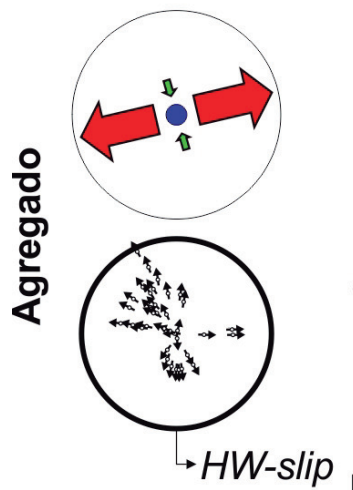

$\rightarrow$ HW-slip

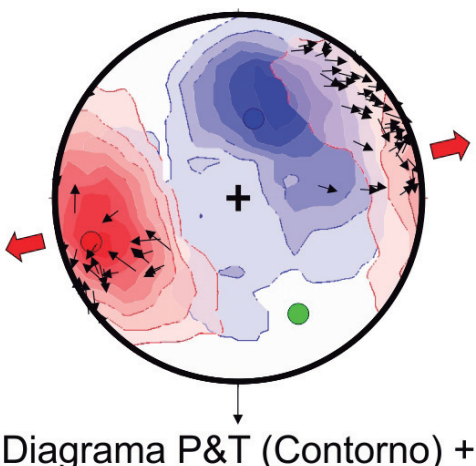

Tangente da Lineação
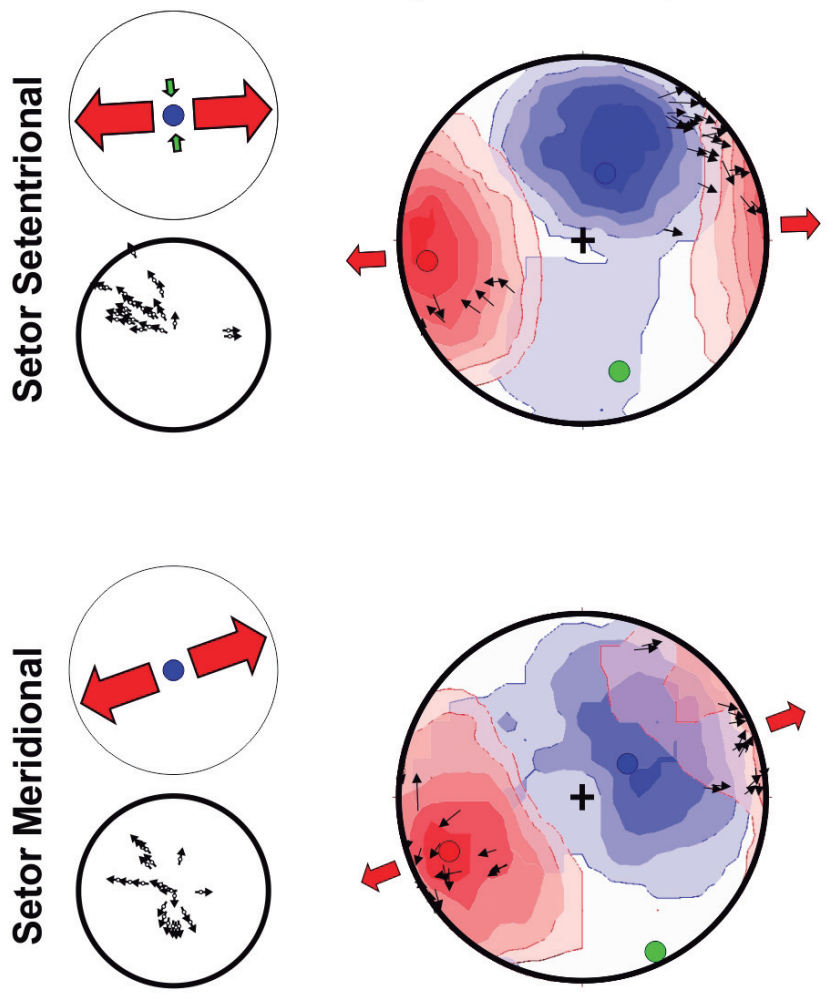
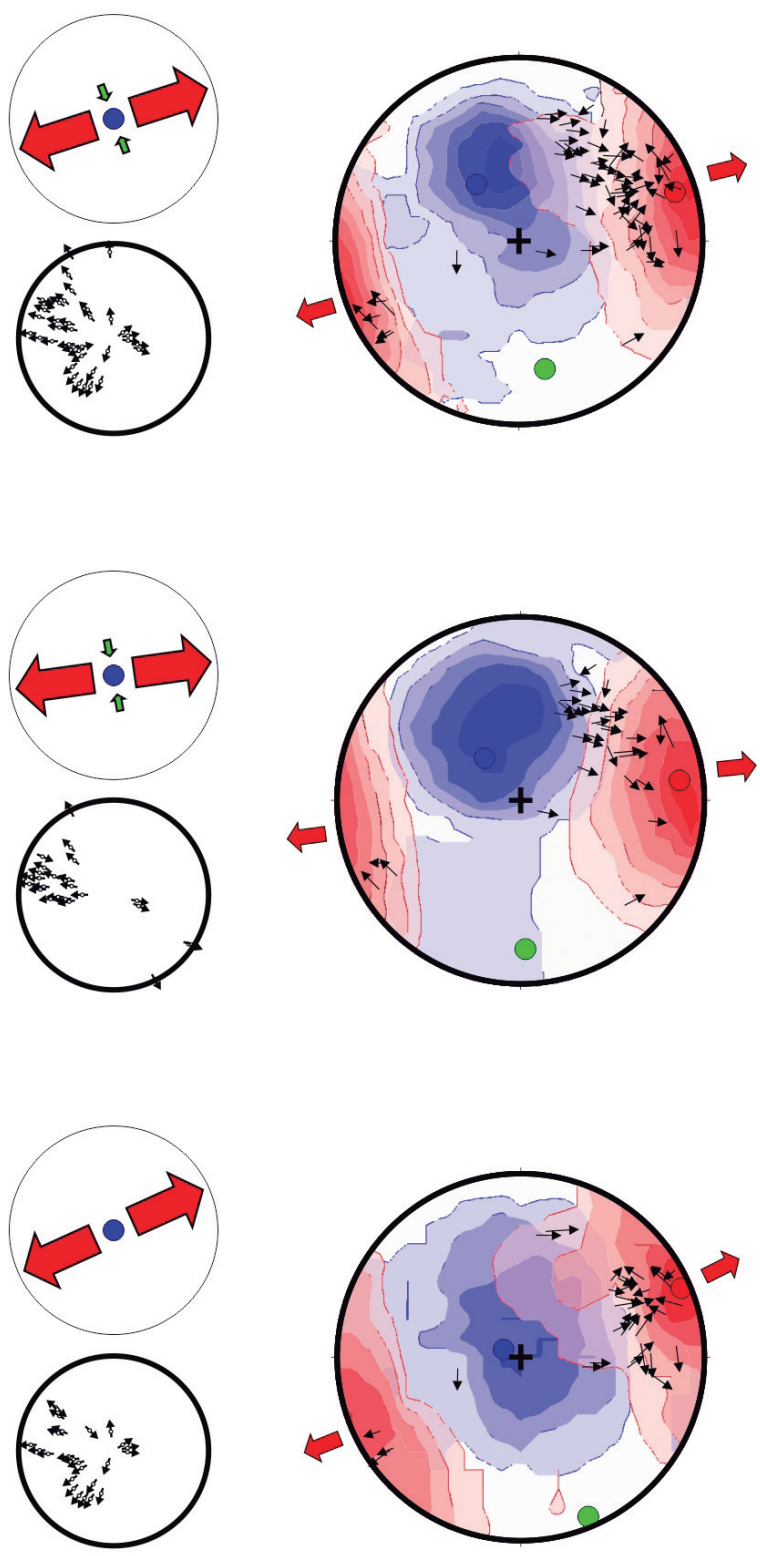

Eixo incremental $\lambda 3(\sigma 1)$

Eixo incremental $\lambda 1(\sigma 3)$

Eixo incremental $\lambda 2(\sigma 2)$

HW-slip: Diagrama de deslizamento do hanging wall indicado pela orientação das estritas $L_{s 0}$

Figura 7. Projeção polar dos eixos incrementais de encurtamento (eixos $\mathrm{P}$ ) e extensão (eixos T) definidos para as superfícies de deslizamento interestratal no bordo oeste da Serra Central com superposição do diagrama tangente de lineação. 
Para os dados brutos obtidos em campo, os diagramas PeT e a solução dos eixos cinemáticos incrementais definidos pelos autovetores s1, s2, s3 (análise Linked Bingham não ponderado) indicam um encurtamento $\mathrm{NNE}$ a NE, com orientação 26/57 quando os dados são tratados de maneira agregada (setor norte + setor sul) (Figura 7). Quando analisados setorialmente, a orientação do encurtamento incremental é de 13/46 e 49/62 para os setores norte e sul, respectivamente. A extensão associada, representada graficamente pelo eixo 11, apresenta caimentos sub-horizontais para WSW a SW - com orientações de 267/15 para o setor norte, de 239/26 para o setor sul e de 258/21 quando tratados de maneira agregada (Figura 7). Ao analisarmos os resultados gráficos apresentados na Figura 7, é possível observar que os valores para s1 e s3 não apresentam variações significantes, quando comparados os dados tratados por setores e de maneira conjunta.

Ao aplicarmos uma rotação de $30^{\circ}$ no sentido horário, é possível notar uma pequena diferença nos resultados obtidos para a direção de extensão. Os resultados dos dados agregados indicam orientações de 325/70 e 79/08 para os eixos incrementais 13 e 11 , respectivamente, configurando uma extensão ENE-WSW. Para o setor norte, a orientação dos eixos e3 e e1 é de 337/61 e 87/10, enquanto no setor sul esses eixos mostram orientação de 314/80 e 61/02 (Figura 7).

\section{DISCUSSÃO E INTERPRETAÇÃO}

O domínio da Serra Central registra ao menos dois eventos tectônicos formadores de bacia, representados pelos riftes Sítio Novo e Macaúbas, anteriores à formação da Bacia Bambuí, que foram afetados pelos processos de inversão tectônica na porção noroeste da faixa Araçuaí no Brasiliano (Bersan, 2015). Para a formação da bacia que acolheu os sedimentos do Grupo Sítio Novo não foram encontradas evidências estruturais na área. No entanto, Danderfer e Dardenne (2002) associam a sua deposição a uma tectônica extensional, responsável por configurar um sistema de riftes submeridiano no interior do paleocontinente Rodínia. No domínio fisiográfico do Espinhaço Setentrional, Danderfer (2000) caracterizou um hemigráben para explicar o preenchimento sedimentar do Grupo Sítio Novo, com depocentro disposto ao longo da falha de Santo Onofre. Essa estrutura se estenderia para o sul por centenas de quilômetros e teria a falha de Santo Onofre como um dos principais acidentes tectônicos do rifte Sítio Novo, conforme constado por Costa (2013) ao analisar a evolução tectono-estratigráfica da Serra Geral, imediatamente ao leste da região aqui investigada.

Bersan (2015) considera que a sucessão do Grupo Sítio Novo aflorante na Serra Central também constitui o registro do preenchimento de um hemigráben, interno ao sistema de rifteamento intracontinental regional, porém definindo uma sub-bacia distinta daquela desenvolvida ao leste. Nesse cenário, o autor interpretou uma borda de falha com orientação $\mathrm{NNW}$, trajetória lístrica e mergulho para leste, com base em dados geofísicos e no estilo estrutural imposto às rochas supracrustais. $\mathrm{O}$ embasamento arqueano-paleoproterozoico materializado pelo BIMA definiria um alto estrutural relativo do sistema, isolando a sub-bacia da Serra Central daquelas nucleadas ao leste (no domínio da Serra Geral), conforme ilustrado pela Figura 8A. A ausência de conglomerados na porção leste da Serra Central corroboraria a proposta do desenvolvimento de uma borda flexural em direção ao BIMA (Bersan, 2015). A sedimentação da sequência siliciclástica correlacionada ao Grupo Sítio Novo descrita na Serra Central é compatível com ambiente marinho raso. A presença de leitos de conglomerados no bordo oeste provavelmente sugere um aporte sedimentar proveniente de uma possível borda de falha, com área-fonte definida pelo alto de Januária (Figura 8A).

De acordo com a literatura mais recente, a sucessão basal do Grupo Macaúbas é interpretada como o preenchimento de um rifte Toniano/Criogeniano decorrente da fragmentação do supercontinente Rodínia (Pedrosa-Soares e Alkmim, 2011). Os diamictitos da Formação Serra do Catuni, ocorrentes ao longo da borda oeste da Serra Central, corresponderiam a depósitos glaciogênicos mais proximais à borda de falha da bacia. Evidências estruturais para a tectônica rifte da bacia Macaúbas são raramente descritas na literatura. Hercos et al. (2008) interpretaram hemigrábens preenchidos por diamictitos em seção sísmica levantada no domínio norte da Serra do Cabral. No Espinhaço Setentrional, Danderfer (2000) interpreta uma tectônica transtrativa destral para a formação do rifte Santo Onofre, considerado por vários autores como uma extensão do rifte Macaúbas na porção norte do cráton São Francisco (p.ex., Schobbenhaus, 1996; Danderfer e Dardenne, 2002; Alkmim et al., 2001). Uma interpretação para a geometria do rifte Macaúbas na área estudada é dificultada pela falta de exposições dos elementos associados com a suposta tectônica extensional (falha de borda, falhas subsidiárias e bloco alto). Aqui é empregada a proposta de uma geometria em hemigráben conforme interpretado por Hercos et al. (2008) e Danderfer (2000) para o Espinhaço Meridional e Setentrional, respectivamente, para explicar a deposição do Grupo Macaúbas e o basculamento das camadas do Supergrupo Espinhaço (Figura 8B). Essa geometria varia em função do mergulho da borda de falha principal, a qual, posteriormente, teria controlado o processo de inversão e encurtamento das camadas no interior da bacia (p.ex., Danderfer, 2000; Gomes et al., 2006; Yagupsky et al., 2008).

Ao longo da borda oeste da Serra Central, foram encontrados registros estruturais cuja gênese possivelmente se relaciona com o desenvolvimento da bacia Macaúbas. Esses registros incluem superfícies de deslizamento 
interestratais, materializadas pelas $\mathrm{L}_{\mathrm{S} 0}$ e pelos ressaltos associados, além de famílias de veios sigmoidais indicativos de movimentação normal, que teriam se formado pela acomodação da deformação do hanging wall edificado pelas rochas do Grupo Sítio Novo junto a uma borda de falha. As análises de paleostress favorecem essa interpretação e permitem inferir um regime tectônico extensional para a bacia Macaúbas.

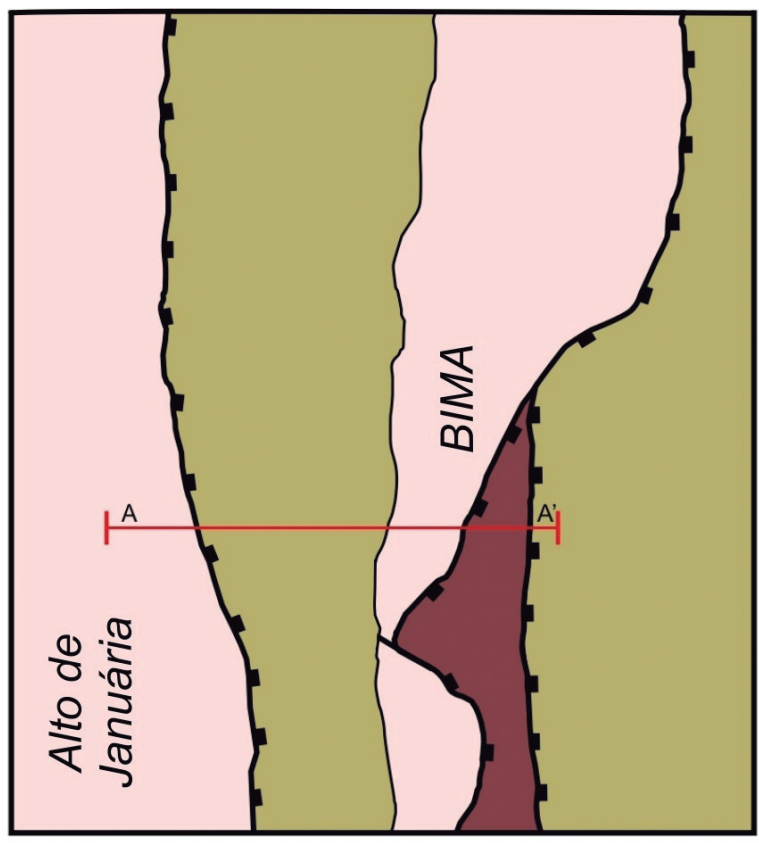

ـ. Falha normal

Rifteamento Neoproterozoico Grupo Macaúbas/Santo Onofre Rifteamento Esteniano Grupo Sítio Novo - Supergrupo Espinhaço

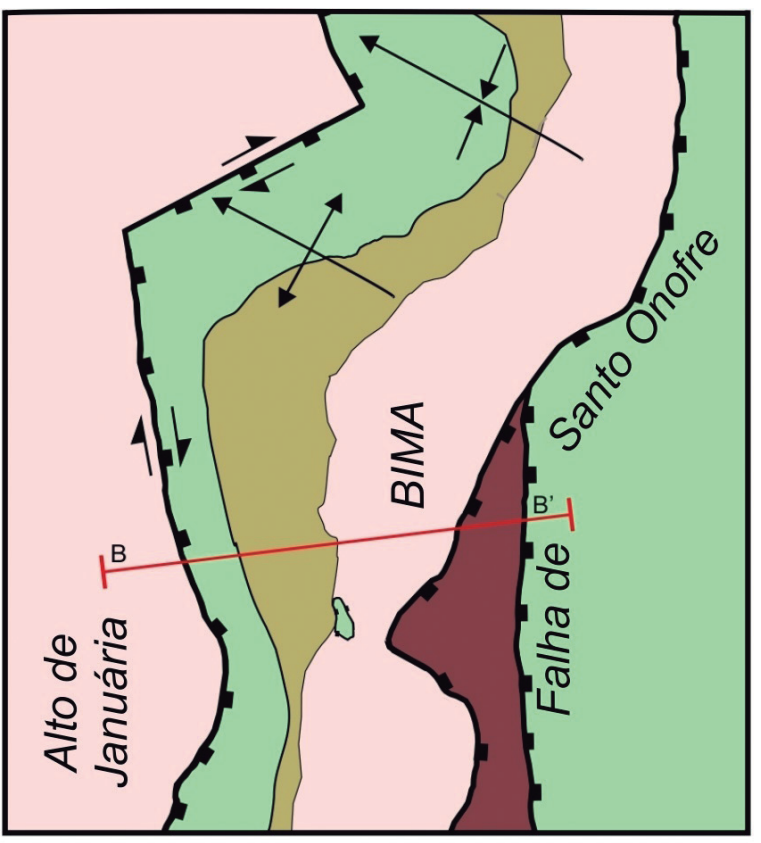

Rifteamento Calimiano

Grupo Mato Verde - Supergrupo Espinhaço

\section{Embasamento Arqueano/Paleoproterozoico}
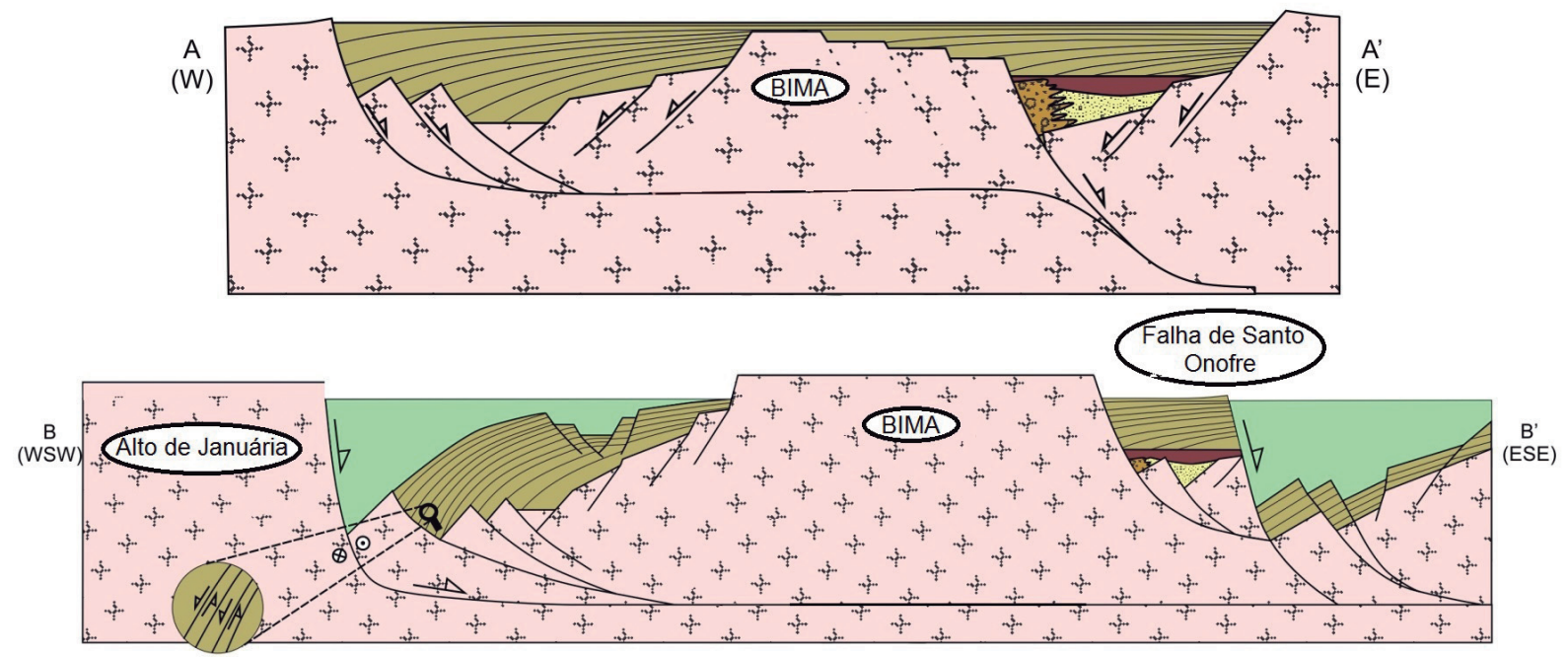

BIMA: Bloco Itacambira-Monte Azul.

Figura 8. Modelo tectônico hipotético para explicar a evolução da área. (A e perfil A-A') Evento I de rifteamento relativo à deposição das rochas do Supergrupo Espinhaço; (B e perfil B-B') evento de rifteamento superposto ao evento I, relativo à colocação do Grupo Macaúbas e à deformação do hanging wall formado pela sucessão do Grupo Sítio Novo. 
As estrias de atrito desenvolvidas sobre planos de acamamento apresentam média a alta obliquidade, com ressaltos normalmente indicando cinemática normal destral. Caso o deslizamento interestratal que originou essas estruturas decorresse de dobramentos relacionados com a compressão e com o encurtamento ocasionados pela inversão Brasiliana, a cinemática dominante deveria se apresentar reversa e com fluxo em direção às zonas de charneira (p.ex., Erslev e Mayborn, 1997; Johnson e Johnson, 2000; Fossen, 2010). No entanto, isso não ocorre na região estudada. Dessa forma, tais estruturas parecem indicar que o deslizamento ocorreu durante um evento extensional que causou um basculamento das camadas do hanging wall no decorrer do evento de rifteamento Macaúbas. Situações similares em que o basculamento das camadas favoreceu o desenvolvimento de deslizamento interestratal foram descritas por Ferrill et al. (1998) e Williams e Vann (1987). Os diagramas de PeT obtidos a partir das relações entre o plano de $\mathrm{S}_{0}$ e as estrias de atrito indicam que o esforço máximo para gerar o deslizamento flexural da área tende a ser subvertical, compatível com um campo de esforços atuantes em uma tectônica extensional (Figura 7).

Durante a tectônica extensional da bacia Macaúbas, o espesso pacote sedimentar do Grupo Sítio Novo já se encontraria em condições de confinamento no interior de um rifte $\mathrm{e}$, com isso, mecanicamente apto a experimentar o processo de deslizamento interestratal. Em regimes extensionais, o campo de esforços pode ser avaliado a partir de estrias em falhas, com a direção de s3 normalmente marcando a direção de extensão regional. As estrias interestratais aqui descritas estão relacionadas com a deformação do hanging wall, sob um campo de esforços local e, em princípio, independente do campo de esforços regional. O campo de paleostress para o deslizamento interestratal da borda oeste da Serra Central forneceu as seguintes atitudes médias dos eixos principais de stress: $\sigma 1-26 / 57 ; \sigma 2-159 / 23 ; \sigma 3-258 / 21$ (Figura 7). Essas orientações são sugestivas de uma extensão segundo a direção ENE-WSW para o rifteamento Macaúbas. No entanto, os diagramas de deslizamento interestratal do hanging wall (Figura 7 - HW-slip) mostram uma tendência de movimentação segundo a orientação NW-SE para a acomodação da deformação nas rochas do Grupo Sítio Novo.

O bloco diagrama da Figura 9 mostra as relações entre o stress no hanging wall, relativamente ao campo de stress regional, e o desenvolvimento do deslizamento flexural em resposta a um processo transtrativo destral. É incomum o desenvolvimento de estrias interestratais por tectônica extensional frontal quando as camadas experimentam pouca rotação e, consequentemente, adquirem baixo mergulho contra a falha. Estrias têm sido observadas nos casos em que ocorre maior rotação do hanging wall, fazendo com que os estratos adquiram maior mergulho e favoreçam o deslizamento interestratal (Ferrill et al., 1998). Apesar de o desenvolvimento de deslizamento flexural em sistemas extensionais ser dificultado em função do posicionamento quase perpendicular do $\sigma 1$ em relação ao acamamento, a rotação atuante nos estratos durante a evolução do rollover reposiciona as camadas em relação a $\sigma 1$, favorecendo o escorregamento interestratal e o desenvolvimento de estrias de movimento (Bischke e Suppe, 1990). Além disso, foi proposto por Dula (1991) e Matos (1993), a partir de trabalhos de modelagem, que a atuação de um cisalhamento antitético sobre os estratos do hanging wall durante um evento tectônico extensional é responsável pelo desenvolvimento de rollovers de alto mergulho e com grande rotação dos estratos, causando, por consequência, o desenvolvimento de uma bacia sedimentar estreita e profunda.

Posto isso, interpreta-se que as rochas do Supergrupo Espinhaço foram deformadas durante a tectônica formadora da bacia Macaúbas, configurando uma geometria rollover e com camadas apresentando elevado mergulho próximo à borda de falha, em função de um processo transtrativo destral e sob atuação de um cisalhamento antitético (Figura 8). Isso explicaria as orientações de paleostress e de deslizamento interestratais levantadas na área. O desenvolvimento do rollover seria, ainda, controlado pela rotação de blocos do embasamento no sentido da borda de falha principal (Figura 8). Segundo os critérios propostos por Anderson (1951), a orientação da falha mestra em sistemas extensionais normalmente se posiciona perpendicular à direção de máxima extensão $(\sigma 3)$. Dessa forma, consideramos que a direção obtida para a extensão do hanging wall indicaria uma falha com orientação NNW-SSE (Figura 8). Essa direção

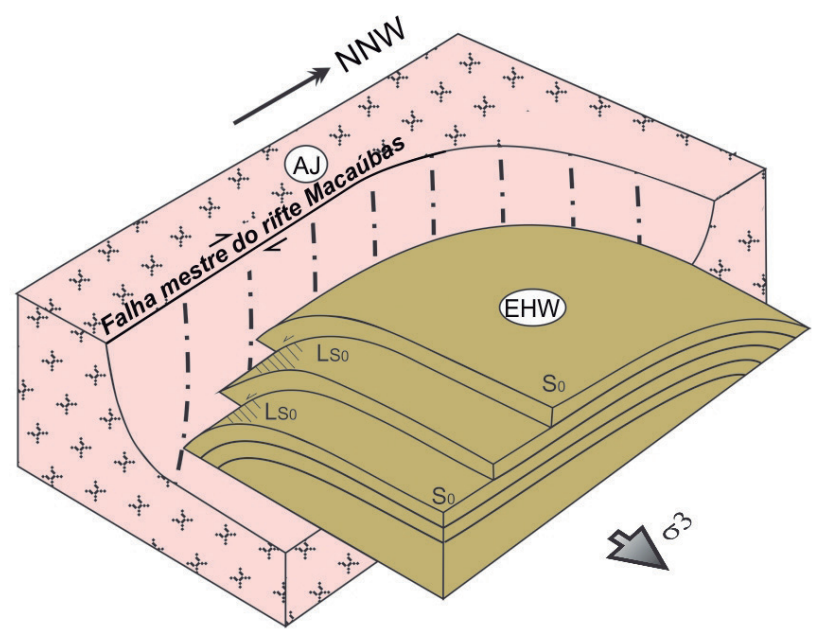

Figura 9. Desenho esquemático ilustrando o desenvolvimento da $L_{\text {so }}$ na estrutura rollover sobre um regime extensional NW-SE na região do alto de Januária (AJ); (EHW) hanging wall edificado pela sucessão do Grupo Sítio Novo. 
coincide com a orientação do contato entre as rochas do Grupo Macaúbas e do Supergrupo Espinhaço, refletindo certo controle na edificação morfoestrutural da Serra Central (Figuras 2 e 8). Para acomodar a grande rotação do rollover, interpreta-se a falha mestra com alto ângulo de mergulho para leste que se encurva em profundidade, vindo a se horizontalizar.

\section{CONCLUSÕES}

A análise das estruturas extensionais observadas sobre os estratos do Grupo Sítio Novo aflorantes na borda oeste do domínio morfológico da Serra Central permitiu estabelecer as seguintes considerações sobre o evento de rifteamento que acolheu os sedimentos da sucessão basal do Grupo Macaúbas nessa região:

1. O rifteamento responsável pela deposição das rochas do Grupo Sítio Novo possivelmente constitui o registro do preenchimento de um hemigráben que define uma sub-bacia distinta daquela desenvolvida na região da Serra Geral;

2. A sucessão do Grupo Sítio Novo se comporta como hanging wall do evento de rifteamento Macaúbas. A deformação do bloco da capa durante a extensão causou a rotação de camadas do Grupo Sítio Novo, de forma a desenvolver um rollover com alto mergulho contra a borda de falha mestra do rifte Macaúbas;

3. A rotação dos estratos do hanging wall durante a evolução do rollover reposiciona as camadas em relação ao $\sigma 1$ e propicia a nucleação das lineações interestratais e dos veios indicativos de movimentação normal a normal destral;

4. A borda de falha do rifte Macaúbas apresentaria uma geometria lístrica com alto ângulo de mergulho para leste e seria orientada segundo a direção NNW-SSE, coincidente com o contorno ocidental da Serra Central;

5. Os diagramas de PeT obtidos para o bordo oeste da Serra Central indicam que a extensão associada ao rifteamento Macaúbas se deu segundo a direção ENE-WSW;

6. O diagrama de deslizamento obtido para as estrias desenvolvidas sobre os estratos do hanging wall fornece uma tendência da acomodação da deformação segundo a direção NW-SE para a extensão do rifte Macaúbas na região da Serra Central. Essa extensão indica a atuação de um processo tectônico transtrativo destral para a abertura do rifte Macaúbas.

\section{AGRADECIMENTOS}

Os autores agradecem o suporte financeiro providenciado pela Fundação de Amparo à Pesquisa do Estado de Minas
Gerais (FAPEMIG - CRA-APQ-00125-12) e o apoio operacional do Instituto Estadual de Florestas - Minas Gerais (IEF-MG) - Parque Caminho dos Gerais. À Coordenação de Aperfeiçoamento de Pessoal de Nível Superior (CAPES), pela concessão de uma bolsa de mestrado (S.M. Bersan). Agradecemos também aos revisores anônimos pelos comentários e pelas sugestões que ajudaram a melhorar o conteúdo deste trabalho.

\section{REFERÊNCIAS}

Alkmim, F. F., Brito Neves, B. B., Alves, J. A. C. (1993). Arcabouço tectônico do Cráton do São Francisco - uma revisão. In: J. M. Dominguez, A. Misi (Eds.). O Cráton do São Francisco. Reunião preparatória do II Simpósio sobre o Cráton do São Francisco, 45-62. Salvador: SBG/NBA-SE.

Alkmim, F. F., Marshak, S., Fonseca, M. A. (2001). Assembly West Gondwana in the Neoproterozoic: Clues from the São Francisco craton region, Brazil. Geology, 29(4), 319-322.

Alkmim, F. F., Marshak, S., Pedrosa-Soares, A. C., Peres, G. G., Cruz, S. C. P., Whittington, A. (2006). Kinematic Evolution of the Aracuaí - West Congo orogen in Brazil and Africa: Nutcracker tectonics during the Neoproterozoic assembly of Gondwana. Precambrian Research, 149, 43-64.

Alkmim, F. F., Martins Neto, M. (2001). A Bacia intracratônica do São Francisco: Arcabouço estrutural e cenários evolutivos. In: C. P. Pinto, M. A. Martins Neto (Eds.) Bacia do São Francisco. Geologia e Recursos Naturais, 9-30. Belo Horizonte: SBG/MG.

Alkmim, F. F., Pedrosa-Soares, A. C., Noce, C. M., Cruz, S. C. P. (2007). Sobre a evolução tectônica do Orógeno Araçuaí-Congo Ocidental. Geonomos, 15(1), 25-43.

Alkmim, F. F., Martins-Neto, M. A. (2012). Proterozoic firstorder sedimentary sequences of the São Francisco craton, eastern Brazil. Marine and Petroleum Geology, 33, 127-139.

Almeida, F. F. M. (1977). O cráton do São Francisco. Revista Brasileira de Geociências, 7, 349-364.

Anderson, E. M. (1951). The Dynamics of Faulting and Dyke Formation with Applications to Britain. Edinburgh: Oliver and Boyd.

Babinski, M., Pedrosa-Soares, A. C., Trindade, R. I. F., Martins, M., Noce, C. M. (2012). Neoproterozoic glacial deposits from the Araçuaí orogen, Brazil: Age, provenance and correlations with the São Francisco craton and West Congo belt. Gondwana Research, 21, 451-465. 
Bersan, S. M. (2015). Análise estrutural do embasamento e da cobertura no extremo norte do Cinturão de Cavalgamentos da Serra do Espinhaço. Dissertação (Mestrado). Ouro Preto: Departamento de Geologia - UFOP.

Bertoldo, A. L. (1993). Comportamento estrutural dos supergrupos São Francisco e Espinhaço e do embasamento entre a serra do Espinhaço setentrional e as serras de Monte Alto (BA) e Central (MG). Dissertação (Mestrado). Rio de Janeiro: Instituto de Geociências - UFRJ.

Bischke, R. E., Suppe, J. (1990). Geometry of Rollover: Origin of Complex Arrays of Antithetic and Synthetic Crestal Faults. AAPG Bulletin, 74, 611.

Cawood, P. A., Strachan, R. A., Pisarevsky, S. A., Gladkochub, D. P., Murphy, J. B. (2016). Linking collisional and accretionary orogens during Rodinia assembly and breakup: Implications for models of supercontinent cycles. Earth and Planetary Science Letters, 449, 118-126.

Costa, A. F. O. (2013). Estratigrafia e tectônica da borda oeste do Espinhaço Central no extremo norte da faixa Araçuaí. Dissertação (Mestrado). Ouro Preto: Departamento de Geologia - UFOP.

Crocco-Rodrigues, F. A., Guimarães, M. L. V., Abreu, F. R. de, Belo de Oliveira, O. A., Greco, F. M. (1993). Evolução tectônica do Bloco Itacambira-Monte Azul entre Barrocão e Porteirinha (MG). IV Simpósio Nacional De Estudos Tectônicos. Resumos, 212-216. Belo Horizonte: SBG.

Danderfer, A. (2000). Geologia Sedimentar e Evolução Tectônica do Espinhaço Setentrional. Tese (Doutorado). Brasília: Instituto de Geociências - UnB.

Danderfer, A., Dardenne, M. A. (2002). Tectonoestratigrafia da bacia Espinhaço na porção centro-norte do cráton do São Francisco: registro de uma evolução poli-histórica descontínua. Revista Brasileira de Geociências, 32(4), 449-460.

Danderfer, A., Lana, C. C., Nalini, H. A., Costa, A. F. O. (2015). Constraints on the Statherian evolution of the intraplate rifting in a Paleo-Mesoproterozoic paleocontinent: New stratigraphic and geochronology record from the eastern São Francisco craton. Gondwana Research, 28(2), 668-688.

Danderfer, A., Waele, B. D., Pedreira, A. J., Nalini, H. A. (2009). New geochronological constraints on the geological evolution of Espinhaço basin within the São Francisco Craton - Brazil. Precambrian Research, 170, 116-128.

Drumond, J. B. V., von Sperling, E., Raposo, F. O. (1980). Projeto Porteirinha-Monte Azul. Belo Horizonte: DNPM-CPRM. 559 p.
Dula, W. F. (1991). Geometric models of listric normal faults and rollover folds. AAPG Bulletin, 75, 1609-1625.

Erslev, E. A., Mayborn, K. R. (1997). Multiple geometries and modes of fault-propagation folding in the Canadioan thrust belt. Journal of Structural Geology, 19 (3), 321-335.

Ferrill, D. A., Morris, A. P., Jones, S. M., Stamatakos, J. A. (1998). Extensional layer-parallel shear and normal faulting. Journal of Structural Geology, 20(4), 355-362.

Fossen, H. (2010). Structural geology. Cambridge: Cambridge University Press.

Gomes, C. J. S., Martins-Neto, M. A., Ribeiro, V. E. (2006). Positive inversion of extensional footwalls in the southern Serra do Espinhaço, Brazil - insights from sandbox laboratory experiments. Anais da Academia Brasileira de Geociências, 78(2), 331-344.

Guadagnin, F., Chemale Jr., F., Magalhães, A. J., Santana, A., Dussin, I. Takehara, L. (2015). Age constraints on crystal-tuff from the Espinhaço Supergroup: Insight into the Paleoproterozoic to Mesoproterozoic intracratonic basin cycles of the São Francisco Craton. Gondwana Research, 27, 363-376.

Hercos, C. M., Martins-Neto, M. A., Danderfer, A. (2008). Arcabouço estrutural da Bacia do São Francisco nos arredores da Serra da Água Fria (MG), a partir da integração de dados de superfície e subsuperfície. Revista Brasileira de Geociências, 38(2), 197-212.

Hoffman, P. F. (1991). Did the breakout of Laurentia turn Gondwanaland inside out? Science, 252, 1409-1412.

Johnson, K. M., Johnson, A. M. (2000). Localization of layerparallel faults in San Rafael swell, Utah and other monoclinal folds. Journal of Structural Geology, 22, 1455-1468.

Knauer, L. G., Fantinel, L. M., Magalhães, J. T. R., Pereira, D. F. L. C. (2015). Folha Gameleiras, escala 1:100.000. In: A. C. Pedrosa-Soares, E. Voll, L. Profeta (Coords.). Projeto Fronteiras de Minas Gerais. Belo Horizonte: CODEMIG/UFMG. 57 p.

Knauer, L. G., Silva, L. L, Souza, F. B. B., Silva, L. R., Carmo, R. C. (2007). Folha Monte Azul, SD.23-Z-D-II, 1:100.000. Belo Horizonte: UFMG/CPRM. 72 p.

Li, Z. X., Bogdanova, S. V., Collins, A. S., Davidson, A., De Waele, B., Ernst, R. E., Fitzsimons, I. C. W., Fuck, R. A., Gladkochub, D. P., Jacobs, J., Karlstrom, K. E., Lu, S., Natapov, L. M., Pease, V., Pisarevsky, S. A., Thrane, K., Vernikovsky, V. (2008). Assembly, configuration, and break-up history of Rodinia: a synthesis. Precambrian Research, 160, 179-210. 
Marrett, R., Allmendinger, R. W. (1990). Kinematic analysis of fault-slip data. Journal of Structural Geology, 12(8), 973-986.

Martins-Neto, M. A., Alkmim, F. F. (2001). Estratigrafia e evolução tectônica das bacias Neoproterozóicas do Paleocontinente São Francisco e suas margens: registro da quebra de Rodínia e colagem de Gondwana. In: C. P. Pinto, M. A. Martins Neto (Eds.). Bacia do São Francisco: Geologia e Recursos minerais. Belo Horizonte: SBG/ MG. p. 31-54.

Martins-Neto, M. A., Pedrosa-Soares, A. C., Lima, S. A. A. (2001). Tectono-sedimentary evolution of sedimentary basins from Late Paleoproterozoic to Late Neoproterozoic in the São Francisco craton and Araçuaí fold belt, eastern Brazil. Sedimentary Geology, 141/142, 343-370.

Matos, R. M. D. (1993). Geometry of the hanging wall above a system of listric normal faults - a numerical solution. $A A P G$ Bulletin, 77(11), 1839-1859.

Moutinho da Costa, L. A., Inda, H. A. V. (1982). O aulacógeno do Espinhaço. Ciências da Terra, 2, 13-18.

Pedrosa-Soares, A. C., Alkmim, F. F. (2011). How many rifting events preceded the development of the Araçuaí West Congo orogen? Geonomos, 19, 244-251.

Pedrosa-Soares, A. C., Babinski, M., Noce, C., Martins, M., Queiroga, G., Vilela, F. (2011). The Neoproterozoic Macaúbas Group (Araçuaí orogen, SE Brazil) with emphasis on the diamictite formations. In: E. Arnaud, G. P. Halverson, G. Shields-Zhou (Eds.). The Geological Record of Neoproterozoic Glaciations. Geological Society, London, Memoirs, 36, 523-534.

Pedrosa-Soares, A. C., Noce, C. M., Alkmim, F. F., Silva, L. C., Babinski, M., Cordani, U., Castaneda, C. (2007). Orógeno Araçuaí: uma síntese 30 anos após Almeida 1977. Geonomos, 15(1), 1-16.

Pedrosa-Soares, A. C., Noce, C. M., Wiedemann, C. M., Pinto, C. P. (2001). The Araçuaí-West Congo orogen in Brazil: An overview of a confined orogen formed during Gondwanland assembly. Precambrian Research, 110, 307-323.
Petit, J. P. (1987). Criteria for the sense of movement on fault surfaces in brittle rocks. Journal of Structural Geology, 9(5/6), 597-608.

Reis, H. L. S. (2011). Estratigrafia e tectônica da Bacia do São Francisco na zona de emanações de gás natural do baixo Rio Indaiá (MG). Dissertação (Mestrado). Ouro Preto: Departamento de Geologia - UFOP.

Reis, H. L. S., Suss, J. (2016). Mixed carbonate-siliciclastic sedimentation in forebulge grabens: An example from the Ediacaran Bambuí Group, São Francisco Basin, Brazil. Sedimentary Geology, 339, 83-103.

Schobbenhaus, C. (1996). As tafrogêneses superpostas Espinhaço e Santo Onofre, Estado da Bahia: revisão e novas propostas. Revista Brasileira de Geociências, 26(4), 265-276.

Souza, J. D., Kosin, M., Heineck, C. A., Lacerda Filho, J. V., Teixeira, L. R., Valente, C. R., Guimarães, J. T., Bento, R. V., Borges, V. P., Santos, R. A., Leite, C. A., Neves, J. P., Oliveira, I. W. B., Carvalho, L. M., Pereira, L. H. M., Paes, V. J. C. (2004). Folha SD.23-Brasília. In: C. Schobbenhaus, J. H. Gonçalves, J. O. S. Santos, M. B. Abram, R. Leão Neto, G. M. M. Matos, R. M. Vidotti, M. A. B. Ramos, J. D. A. Jesus, (Eds.) Carta Geológica do Brasil ao Milionésimo, Sistema de Informações Geográficas-SIG. Programa Geologia do Brasil. Brasília: CPRM.

Uhlein, A., Paim, P. S. G., Tassinari, C. C. G., Pedreira, A. J. (2015). Análise estratigráfica de bacias rifte paleomesoproterozoicas dos crátons Amazônico e São Francisco, Brasil. Geonomos, 23(2), 1-13.

Williams, G., Vann, I. (1987). The geometry of listric normal faults and deformation in their hangingwalls. Journal of Structural Geology, 9(7), 789-795.

Yagupsky, D. L., Cristallini, E. O., Fantín, J., Valcarce, G. Z., Bottesi, G., Varadé, R. (2008). Oblique half-graben inversion of the Mesozoic Neuquén Rift in the Malargue Fold and Thrust Belt, Mendoza, Argentina: News insights from analogue models. Journal of Structural Geology, 30(7), 839-853.

Zhao, G. C., Sun, M., Wilde, S. A., Li, S. Z. (2004). A Paleo-Mesoproterozoic supercontinent: assembly, growth and breakup. Earth-Science Reviews, 67, 91-123. 